\title{
ERRATUM
}

\section{Outbreak of Ceftazidime Resistance Due to a Novel Extended-Spectrum $\beta$-Lactamase in Isolates from Cancer Patients}

\author{
LOUIE NAUMOVSKI, JOHN P. QUINN, DEBORAH MIYASHIRO, MARLYNN PATEL, \\ KAREN BUSH, SUSAN B. SINGER, DONNA GRAVES, TIM PALZKILL, \\ AND ANN M. ARVIN \\ Department of Pediatrics, Divisions of Hematology/Oncology and Infectious Diseases, Stanford University \\ School of Medicine, and Clinical Microbiology Laboratory, The Children's Hospital at Stanford, Stanford, \\ California 94305; Department of Medicine, Division of Infectious Diseases, Humana Hospital-Michael \\ Reese, Chicago, Illinois 60616; Medical Research Division, American Cyanamid, Pearl River, \\ New York 10965; Pharmaceutical Research Institute, Bristol-Myers Squibb, Princeton, \\ New Jersey 08540; and Department of Microbiology and Immunology, \\ Baylor College of Medicine, Houston, Texas 77030
}

Volume 36, no. 9, p. 1993, Table 1: In the boxhead, "TEM-23" should read "TEM-26."

Page 1994, Table 3, columns 3 and 4: The columns of data under the headings "TEM-9" and "TEM-26" should be transposed. 